\title{
USING STRATEGIC PLANNING IN SUPPORT OF DEFENSE ACQUISITIONS
}

\author{
Robert K. MURPHY and Scott D. BEACH
}

\begin{abstract}
Our environment is continuously changing. Government must address challenges in global security that includes traditional conflicts as well as catastrophic events, irregular warfare, and disruptive technologies. The economy is just as important, where jobless rates remain high and markets are unstable. The outcome of this will be multiple priorities, all requiring a portion of the budget, which in turn will result in fewer dollars for defense. Fortunately, there are ways to ensure that defense priorities receive the required funding. By following a simple process for developing an analytically-based strategic plan, the defense sector will dramatically improve the chances of acquiring funding. The outcome of this will be to procure best value solutions that support a nation's national security strategy. This will dramatically improve a country's military defense posture. This paper will review the strategic planning process as applied to military force structure and procurement decisions. In addition, the paper will discuss the Force Matrix Model, a key analysis tool to identify and assess best value solutions within this strategic planning paradigm.
\end{abstract}

Keywords: defense planning, force structuring, airpower, capabilities, procurement, decision support, multi-attribute value theory, analytical hierarchy process.

\section{Introduction}

National security guidelines specify that the defense community must provide military security for the country. So, how does the military make force structure and acquisition decisions in this context? A robust and transparent strategic planning process will help stakeholders choose the best solution to meet the country's requirements. This paper will explain a clear, five-step process that will help develop a strategic plan. It will also introduce a tool that will aid in evaluating a set of solutions. The following steps briefly describe the process and will lead to the strategic plan that meets the national security guidelines:

1. Review the national security guidelines. This step will ensure the strategy meets national requirements and determines the framework for the entire process. 
2. Develop a set of scenarios. This step will ensure that possible future situations have been accounted for. It will also ensure the set of strengths, weaknesses, opportunities, and threats have been addressed.

3. Defining the strategy. This step will ensure the vision, mission, and goals are consistent with the national strategy. It will also ensure that the strategy has the right scope and is correctly constrained using the information from the scenarios.

4. Develop the strategy. This step will ensure that the objectives and tasks used to support the mission have been properly identified. It will also help identify required metrics that fit the context of the mission.

5. Deploy the strategy. Finally, the last step will ensure that feasible solutions have been identified and evaluated.

Although the process itself is simple, a significant amount of analysis needs to be performed to ensure that all aspects of the strategy have been addressed. Each of these aspects will be addressed in detail in the paper.

\section{The Need for Strategic Planning}

Today, solid strategic planning is crucial in a continuously changing global environment. A country's defense posture and ultimately national sovereignty depend on it. With today's weak economy, every dollar on defense should be spent wisely and result in the best value. This is especially true when defense priorities are competing against non-defense priorities such as education or health. In the past, many military acquisition decisions were made based on political reasons resulting in little transparency. However; many considerations, as shown in Figure 1, must be taken into account when developing the plan. Similarly, social or education priorities need to take defense considerations into account because without a military presence, other sectors may be put at risk. The question is which priority can be shown to have the most compelling need. The service, whether it is the army, navy, or air force, that can best justify its requirements, will ultimately receive the largest portion of shrinking defense dollars.

\section{Strategic Planning Process - a Top-down Approach}

A top down approach is the key to guaranteeing success. Involving a country's civilian and military leadership at the beginning of the process gains concurrence early on and ensures good communication flow from start to finish. Furthermore, it ensures the respective parts of the strategy from vision down to tasks are joined together and support the national security guidelines. 


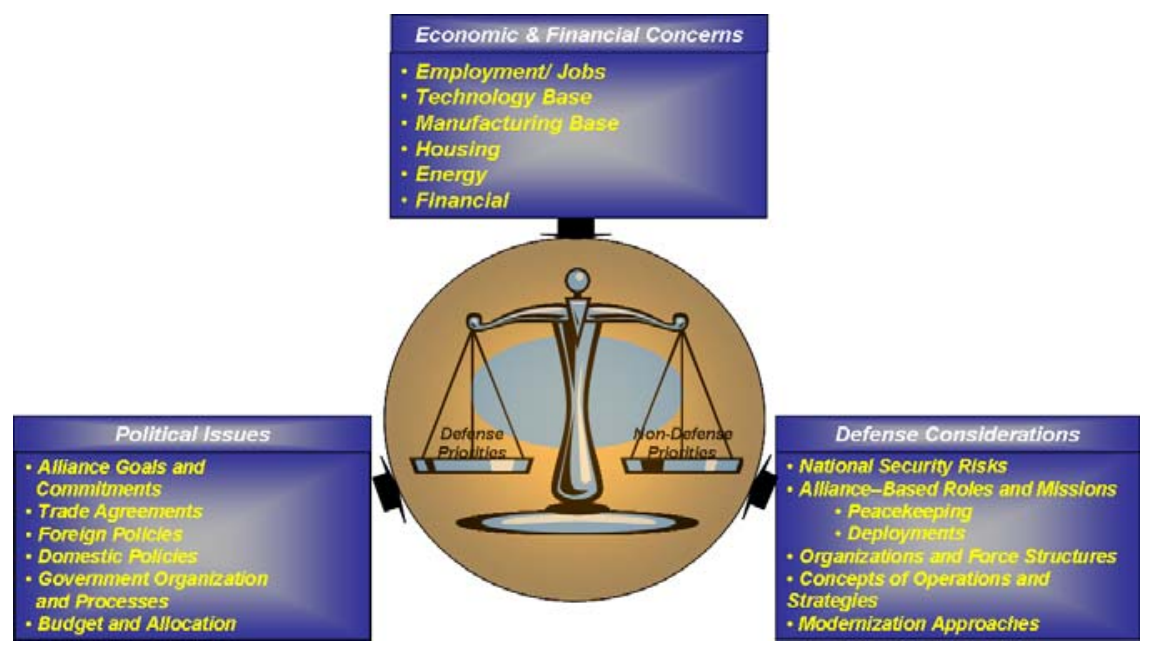

Figure 1: Defense and non-defense considerations and issues.

Before the planning process is started, we must be sure we understand what problem we are trying to solve. In addition, the strategic planning process should lead to the answers to the following questions:

- Who are the stakeholders involved and what influences them (political, economic, social, technological considerations)?

- Why do we need the acquisition? What is the compelling need (vision, mission, and goals)?

- Where will the capability be used? What are the geographical and physical boundaries of the system (environmental conditions)?

- What are the known elements, functions, and gaps of the capability (strengths, weaknesses, opportunities, and threats)?

- When will the capability be needed (timeline)?

- How will the capability accomplish the operation (objectives, tasks and metrics)?

By answering these questions, we can be confident that we have addressed all aspects of a robust strategy. If the questions cannot be answered, then the strategy needs to be refined. 


\section{The Strategic Planning Process Defined}

The strategic planning process shown in Figure 2 will result in a solid strategy and help determine the best acquisition solution. The process starts with reviewing the national security guidelines, followed by: developing the scenario; defining the strategy; developing the strategy; and deploying the strategy. The military strategy, which is the focus of this paper, uses the last four steps in the process to develop the plan and find the solution.

\section{National Security Strategy}

The national security strategy is a document prepared periodically by government leadership. It outlines the major national security concerns and how the government plans to deal with them. A review of the national security strategy as shown in Figure 3 should take into account the perceived and actual threats: military, economic, social, and political. The review should also include other areas such as industry, communications, and transportation. It can also deal with many issues that range from military force preparedness to military force morale. The goal is to make sure the policy addresses all means of securing the sovereignty of the country. Once the assessment is complete, it will be reviewed by policy makers and finally approved by government leadership.

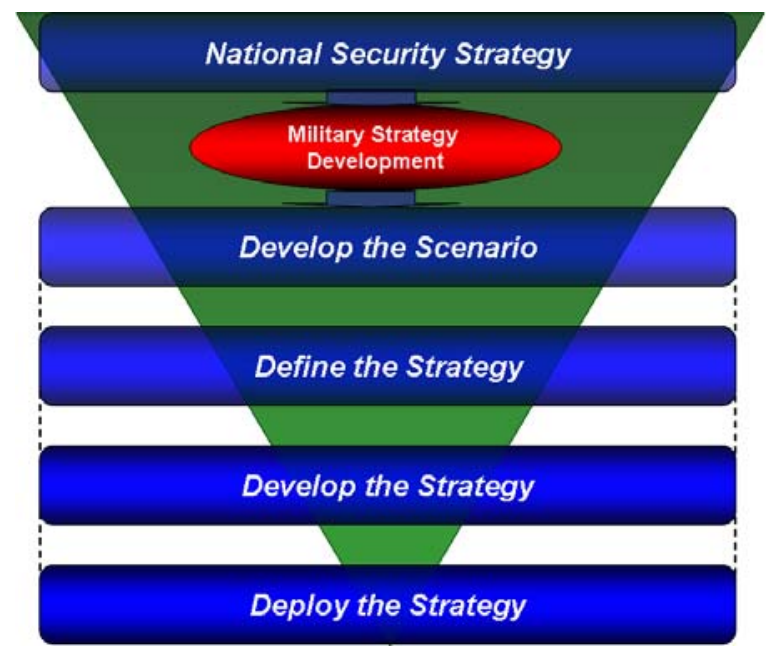

Figure 2: Five steps to the strategic planning process. 


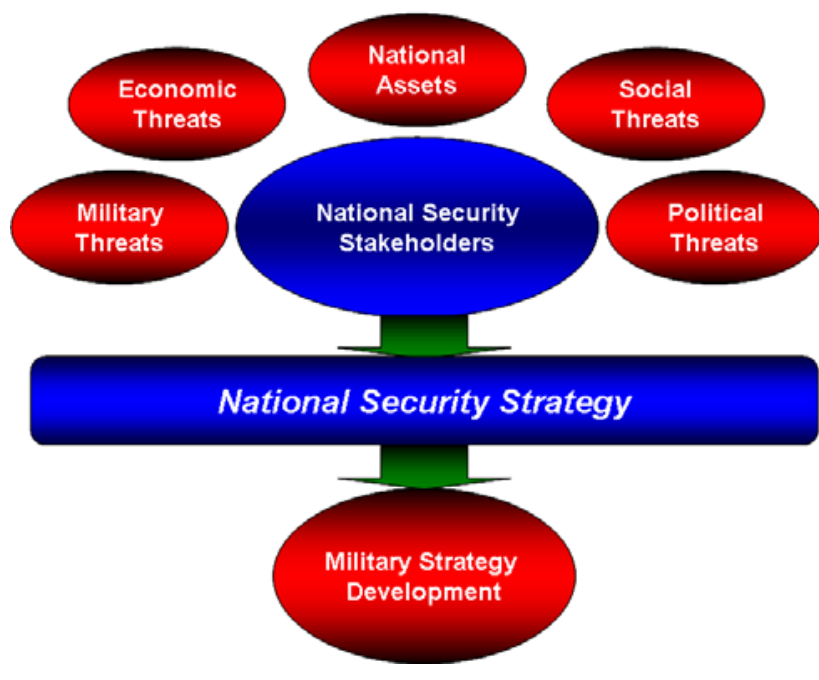

Figure 3: Threat areas of a national security strategy.

A national security strategy provides guidelines for each of the major institutions in government and articulates policy objectives so that each institution can develop specific strategies. A military strategy must be developed that will specify how the defense aspect of national security will be achieved.

Military strategy development creates military service requirements and is consistent with the most recent national security strategy prescribed by a country's leadership. It defines the military vision, mission, goals, objectives, tasks and force structure solutions that address global, regional and internal threats. The process also produces operational concepts to deal with these threats. It then looks at the adequacy of current military capabilities and risk to meet the threat given the current environment. Armed with national strategy and the military strategy as a guide, scenario development can begin.

\section{Develop the Scenario}

Developing the strategy starts with scenario planning shown in Figure 4 and is the second step in the process. Scenario planning is essentially a look at future possibilities or "what if" situations that might exist. It is based on anticipated threats, environmental conditions, and trends, while trying to predict risks and unintended consequences. 


\section{Develop the Scenario}

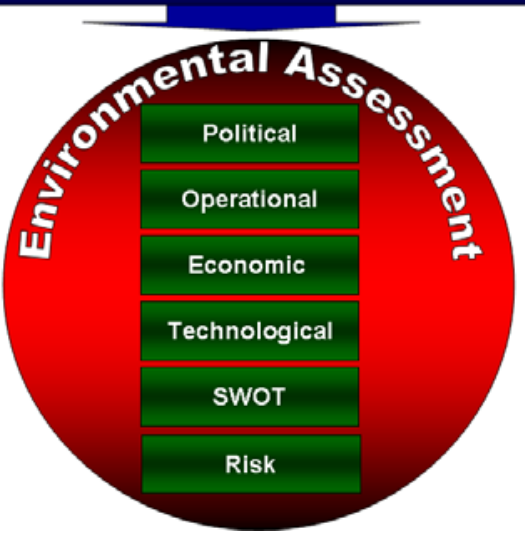

Figure 4: Developing the scenario.

Scenario planning should:

- Use external factors and trends to develop a story for each situation;

- Develop details about how the scenario came to happen;

- Include uncertainties when creating a scenario;

- Write the story into a script;

- Help develop responses to situations;

- Help ensure that requirements support the scenario.

In scenario development, it is important to develop alternate scenarios that address different major possible outcomes; to describe the scenario so that it is well understood by all stakeholders; and to look at different scenarios based on different assumptions. The ultimate goal of the process is to identify force structures and acquisition solutions that can adapt to as many scenarios as possible.

\section{Environmental Assessment}

The environmental assessment can look at any area, internal or external, that may impact the strategy. A suggested way to assess the environment is to use the factors in Figure 4. Others may include societal, legal, or demographic. These factors must relate to the current problem to be solved. For example, since this paper examines strategic planning in support of defense acquisitions, the factors should be defense related. Some of the factors are described below and can be helpful in identifying important issues: 
- Political. These factors are how and to what degree other parts of the government play a role in military acquisitions. Specifically, political factors may include areas such as tax policy, labor law, environmental law, trade restrictions, tariffs, and political stability. But especially important is how political factors can influence the defense budget.

- Operational. These factors include items that range from the strategic level down to the tactical level that could affect the strategy. For example, the lack of good operational communication between the fighter aircraft and ground forces can have significant adverse consequences when trying to accomplish a mission.

- Economic. These factors can include economic growth, interest rates, and inflation rates. These factors have major impacts on procurement decisions. For example, economic growth (or decline) affects how much budget the military has for new procurements or how much funding they have for sustainment activities. Currently, most countries devote between 2 and 4 percent of their Gross Domestic Product (GDP) to defense. Any negative changes to the economy can have a dramatic impact.

- Technological. These factors can include research \& development spending or type and maturity of emerging technology. They can determine barriers to meeting minimum thresholds for confronting threats. Furthermore, technological shifts can affect costs, quality, and security.

\section{SWOT (Strengths, Weaknesses, Opportunities, and Threats)}

A SWOT analysis is a very useful method in scenario development that involves identifying factors from the list above that might impact how you respond to a scenario. A layout for a SWOT analysis is shown in Figure 5. The SWOT will be used later in step four (strategy development) and will be used to help develop objectives. The reason it is used in this step is because it takes all of the environmental factors into account.

Internal strengths and weaknesses are the first area of focus. A candid evaluation will provide the right data and could justify a new weapons system. The reverse is also true. Should an internal assessment be completed improperly, with inaccurate data, then the entire process could be flawed and the wrong system ultimately procured. External threats can also be very helpful in determining the best strategy. A good understanding what the threat is, its origin, and what the goals are will help formulate a response to keep them from improperly affecting future acquisition plans. Conversely, where there are threats there are always opportunities and it is important to take advantage of them early on in constructing the strategy. Often opportunities pro- 


\begin{tabular}{|l|l|}
\hline \multicolumn{1}{|c|}{ Strengths (Internal) } & Weaknesses (Internal) \\
\hline $\begin{array}{l}\text { - Political } \\
\text { - Operational } \\
\text { - Economic } \\
\text { - Technological }\end{array}$ & $\begin{array}{l}\text { - Political } \\
\text { - Operational } \\
\text { - Economic } \\
\text { - Technological }\end{array}$ \\
\hline Opportunities (External) & Threats (External) \\
\hline $\begin{array}{l}\text { - Political } \\
\text { - Operational } \\
\text { - Economic } \\
\text { - Technological }\end{array}$ & $\begin{array}{l}\text { - Opelitical } \\
\text { - Economic }\end{array}$ \\
& - Technological \\
\hline
\end{tabular}

Figure 5: Strengths, Weaknesses, Opportunities, and Threats using environmental factors.

vide an alternate way forward that was not previously thought of or can provide new insight that will strongly support the rest of the strategy building process.

By performing an environmental assessment that includes SWOT, a set of scenarios can now be formulated that will begin to focus in on the military requirements and potential solutions. One such scenario might concentrate on the Air Sovereignty Mission. Another might concentrate on supporting the troops on the ground through Close Air Support (CAS). A close evaluation of these scenarios will reveal a broad set of requirements that will be useful in developing acquisition strategies.

\section{Define the Strategy}

The third step, defining the strategy, is where the focus shifts from defining a broad set of scenarios to defining a vision, missions, and goals. Once these are established, a spectrum of operational concepts are developed that address peacetime operations to wartime operations as shown in Figure 6.

\section{Ground Rules and Assumptions (GR\&As)}

GR\&As define the scope and constraints of the strategy. They allow the strategy to move forward when there are unknowns that cannot be resolved or if a set of restrictions are set in place that cannot be overturned. While a ground rule sets a procedure and is generally fixed, an assumption is something that is taken for granted or variable. Although these terms have different meanings, they essentially end with the same result. That is, they can slow down or halt the process entirely if they are not resolved up front. 


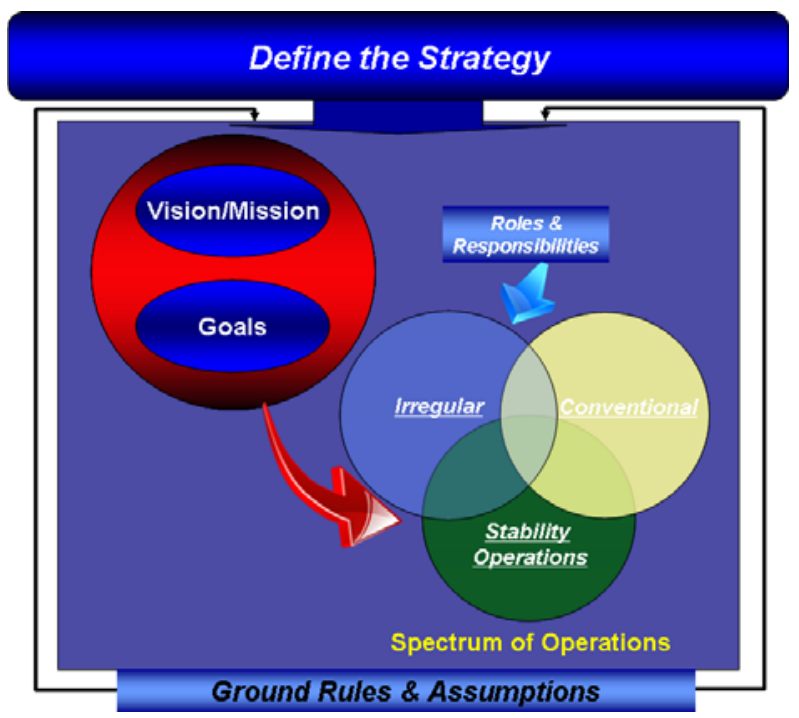

Figure 6: Elements of the Defense Resource Management Model.

\section{Vision}

The vision statement is based on the scenario and is a broad, high level description and explains your response to the scenario. In other words, it describes how you want to shape the future. The vision may be to ally your country to surrounding countries in order to provide stronger common defense or it may be to have the strongest army in place in case of attack. It may be more specific. For example, it may be to provide for a new multi-role fighter aircraft for improved air sovereignty of the homeland. In either case the vision statement will frame the rest of the strategy.

\section{Mission}

The mission statement is a brief purpose statement of what the organization (whether it be defense related or not) will endeavor to bring about. For example, it may be to replace aging aircraft with a multi-role fighter aircraft that has both superior defensive counter air and air-to-ground capabilities. This is one of possibly many missions that might support the vision.

\section{Roles}

Roles (and responsibilities) are often used to assign aspects of a mission to different organizations and can span the spectrum of operations from peacetime to wartime. For example, if the mission is to defend the homeland from the air, the role would probably fall to the Air Force. Essentially, by defining roles and responsibilities, mis- 
sions and goals will be made clearer. In addition, by understanding the required roles, subject matter experts (SMEs) can be identified who can clarify the objectives. These SMEs are an essential part of the strategy team and can offer their guidance and expertise in product development.

\section{Goals}

Goals are tangible and specific, and should describe the final outcome or product desired from the mission. They must be achievable and have an end date. There can be as many goals as required to achieve the mission. For example, there could be a series of goals for a defensive counter air mission. Figure 7 shows four possible truncated goals. The actual goal for "maximize kills" is to maximize the number of enemy aircraft kills for every aircraft sortie.

\section{Develop the Strategy}

Step four in the process includes determining what objectives need to be performed in order to meet the goals. Recall that the objectives are based on the SWOT analysis and may include a need to fill a gap or leverage a strength. The actual action plan is determined by the set of tasks and associated metrics required to meet the objectives.

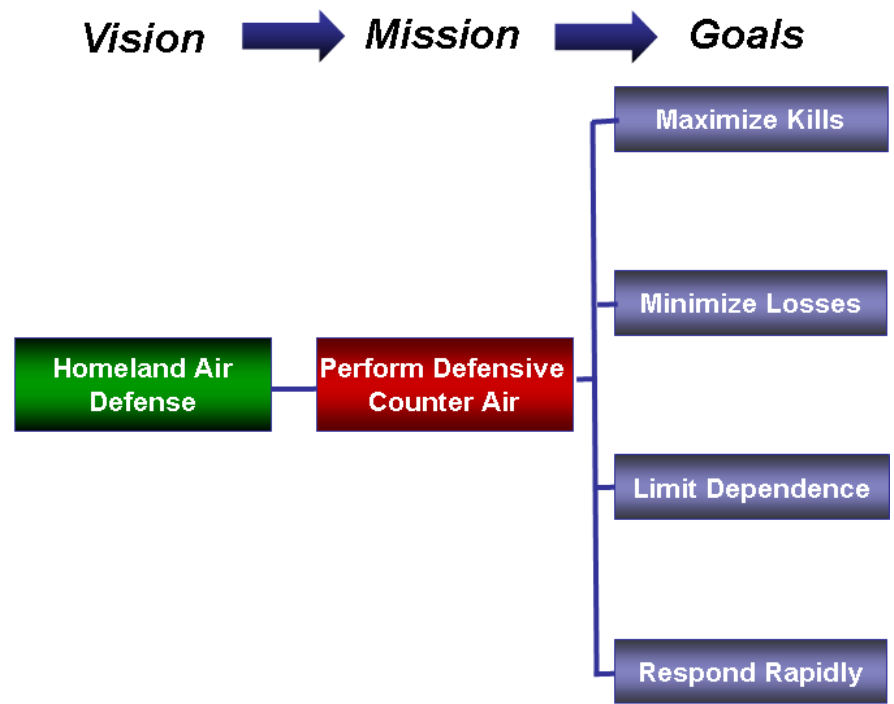

Figure 7: Example hierarchy of vision, mission, and goals. 
The timeline is crucial in the planning stages (Figure 8). It not only helps determine resources, it is a forcing function to stay on schedule and it helps set the timeframe for the scenario. The Scenario timeframe is important because it determines if you will procure existing technology or design, develop, and procure new technology. Finally, the timeline can be driven by internal or external sources like the budget cycles, elections, failure of legacy equipment or simply change in the environment (like an increased threat).

\section{Defining the Objectives}

Defining objectives should use information from the SWOT analysis to identify areas of weakness (gaps) or threats that need to be overcome or by leveraging strengths or seeking new opportunities. By doing this, a description of the internal and external operational factors impacting a mission can be achieved. This method also serves as a check that elements defined in the operational concept have one or more associated objectives. Conversely, each statement of the objective should involve one or more corresponding elements and interfaces to the solution under study. Checking objectives against the operational concept may uncover missed weaknesses or assumptions, or incomplete context within the concept. Figure 9 is a good example of objectives that meet the previous four goals to support defensive counter air.

\section{Determining Tasks}

Tasks can be described as how the objective will be accomplished. For example, in order for an aircraft to accomplish the objective of acquiring and ID targets it must be

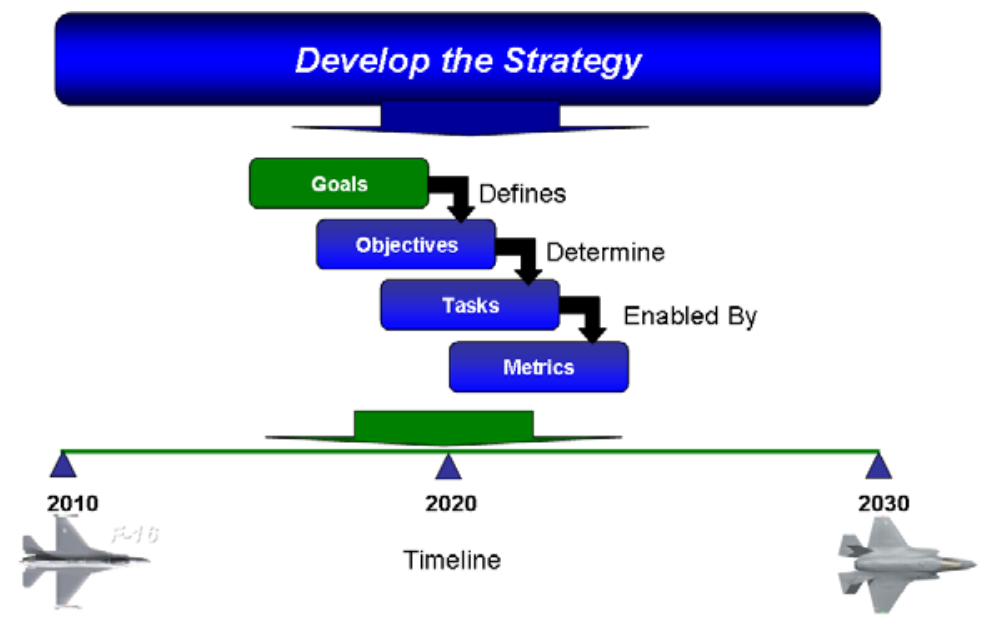

Figure 8: Developing the strategy. 


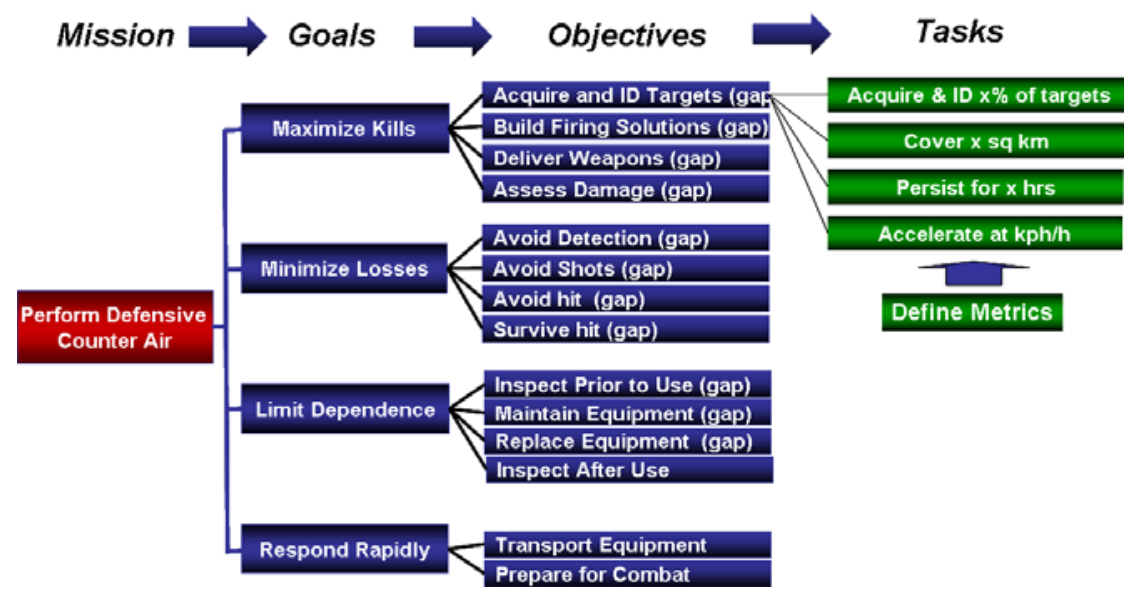

Figure 9: Defining Metrics.

able to accomplish the tasks listed below in figure 9. Tasks are the basic description of a capability and must be measurable so that we know if the solution is meeting its defined goals.

\section{Identifying Metrics}

Metrics are relevant parameters used to quantify the key characteristics (attributes) of tasks in order to determine performance. In other words metrics are required to determine the "goodness" of a capability or task to be performed. It is important that metrics be well understood, since these will be used to perform the gap assessment.

\section{Deploy the Strategy}

Finally, the fifth step in the process, as shown in Figure 10, is deploying the strategy. This step involves identifying the potential solutions that will meet the requirements, formulating concept of operations, performing an analysis of alternatives (gap, cost, and risk assessment) and finally selecting the best solution from a viable set of alternatives.

Because the number of goals, objectives, and tasks can be large, the use of capability based evaluation tools such as the Force Matrix Model ${ }^{\mathrm{TM}}\left(\mathrm{FMM}^{\mathrm{TM}}\right)$ developed by Lockheed Martin Aeronautics Company can be invaluable. These tools can evaluate solutions based on defined criteria and help decision makers determine the best solution. 


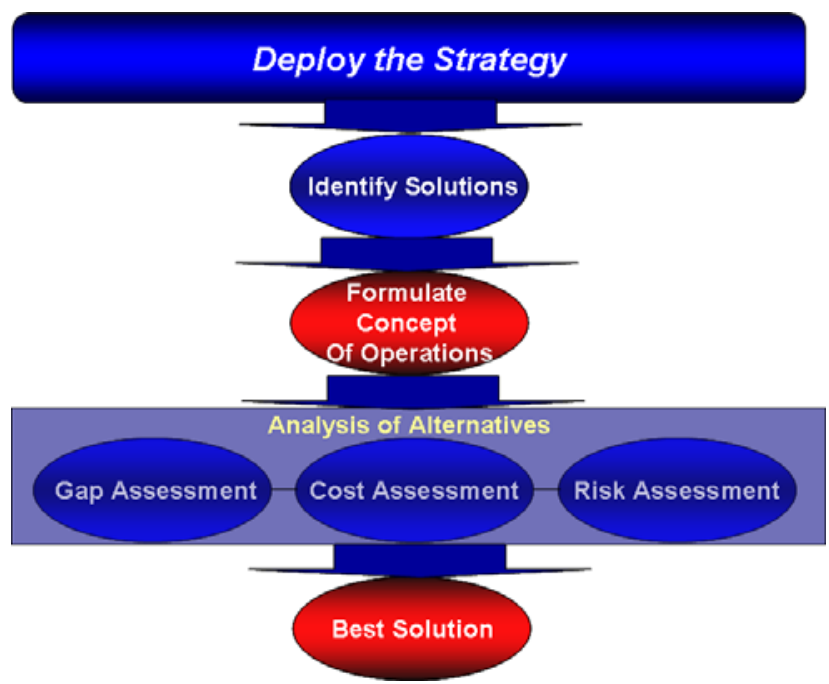

Figure 10: Deploying the strategy.

\section{Identifying Solutions}

Identifying solutions is an important first step in deploying the strategy. Solutions may include technological ones, but can also include non-technical solutions such as changes in doctrine or training. However, for the purposes of this paper, only material solutions are considered. Solutions are chosen by considering all reasonable alternatives that might fill the gaps. Once the solutions are identified, a concept of operations should be developed on how the solutions will be used. This ensures that the objectives developed earlier are properly understood by all stakeholders.

\section{Formulating Concept of Operations}

The concept of operations is an operational view of a strategy. The concept will ensure the solution is meeting (at least conceptually) all of the objectives defined earlier. Based on force structure analysis, threats, or order of battle, operational concepts are developed so that objectives can be clarified. It helps to visually clarify the mission and objectives by:

- Describing a system that everybody agrees on and forcing people to explain their assumptions;

- Clarifying the mission and key issues;

- Understanding interfaces between elements (e.g. aircraft and headquarters) by helping the strategists understand the way elements in the system reinforce or balance one another. 
Figure 11 shows a high-level operational view for an air sovereignty operation. The range rings around the aircraft show the required coverage for the new fighter aircraft in a peace time air sovereignty role. Additional attributes, such as time on station, number of aircraft required, ordnance requirements, rapid deployment requirements, maintenance turn-a-round times can also be added to the concept of operations.

\section{Analysis of Alternatives (AoA)}

AoA is a transparency analysis process designed to ensure that multiple alternatives have been analyzed prior to making costly investment decisions. It is an effort to move from the justification for a single alternative to the best possible solution in a rational, defensible manner considering risk and uncertainty. As with other decisionmaking tools, techniques, and methodologies, AoA is most effectively used in a higher-level decision-making context. AoA is used in the decision-making process to support acquisition of new capabilities and systems. Each service has its own AoA methodology, but the Air Force Materiel Command AoA Handbook ${ }^{1}$ is very well documented and is used to support the strategic planning process in this paper. It is a handbook with useful tools and techniques. United States Department of Defense AoA studies span three main categories of measures: effectiveness, cost, and risk which are discussed below.

\section{Perform Gap (Effectiveness) Assessment}

This is one of the elements of AoA used to measure effectiveness. It is an analysis of how well the solution meets the requirements. This includes current systems and pro-

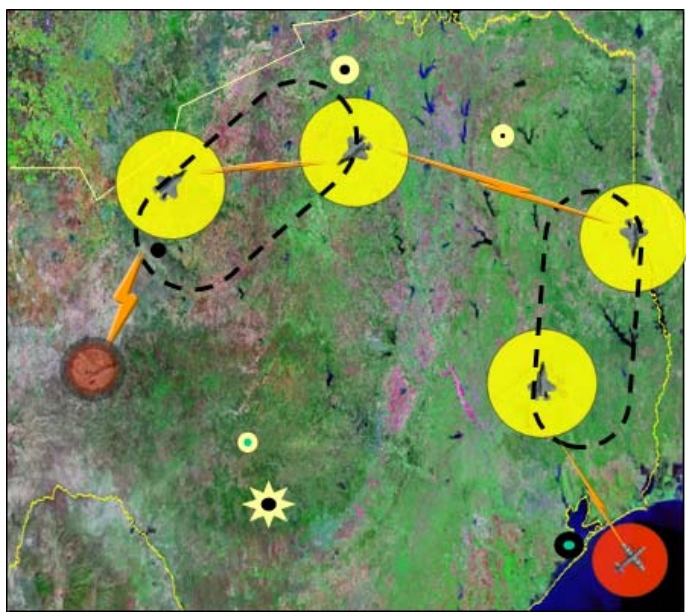

Figure 11: Example of Air Sovereignty operational concepts (operational view). 
posed alternatives. It can be done in two ways. First, it can be done subjectively using a group of Subject Matter Experts (SMEs). This group is familiar with the operational requirements and understands the products that are to be compared. They are normally military personnel, engineers, and analysts who have an understanding of the operation and performance of the product. Second, the assessment can be performed objectively by using a pair-wise comparison process (e.g. Analytical Hierarchy Process) or a multi-attribute value theory method, which will be described later in this paper.

\section{Perform Cost Assessment}

This can include many types of costs including net present value, Through Life Cost, Life Cycle Cost (LCC), Return on Investment (ROI), acquisition cost, procurement cost, research and development cost, Total Ownership Cost (TOC), or Performance Based Logistics (PBL). It is an important consideration and depending on where in the life cycle the alternatives lie. For example, if existing aircraft are available, only Procurement Cost and Operations \& Support Cost are important. But if new technology needs to be developed, the Research and Development costs must be taken into consideration.

\section{Perform Risk Assessment}

This can be applied to both performance and cost, and involves identifying where the organization might be vulnerable to internal or external threats or where a system capability is subject to risk. The purpose of a risk assessment is to try and identify as many risks as possible so you can prepare contingencies. For example, an aircraft might have very good performance on paper, but if the design is still in the technology demonstrator phase, then it might be judged to be high risk and a mitigation plan must be determined to reduce the risk. In addition to risk, it might be necessary to determine the consequence of that risk. For example, two new systems might have a high schedule risk because of new technology, but the consequence of schedule slip might be low because one vendor has been developing and testing the technology for years. Remember that the greater the risk, the greater the potential for failure.

\section{Structuring the Assessment using Force Matrix Model ${ }^{T M}$}

The entire AoA assessment can be captured by using tools such as the Force Matrix Model $^{\mathrm{TM}}$. Figure 12 shows a matrix of elements from an aircraft assessment, while Figure 13 shows how the elements from the assessment are laid out in a hierarchical structure. As shown in Figure 12, capability gap assessments are performed for each alternative under each mission, goal, and objective. Also, cost and risk (schedule, cost, and performance) are determined for each alternative. 

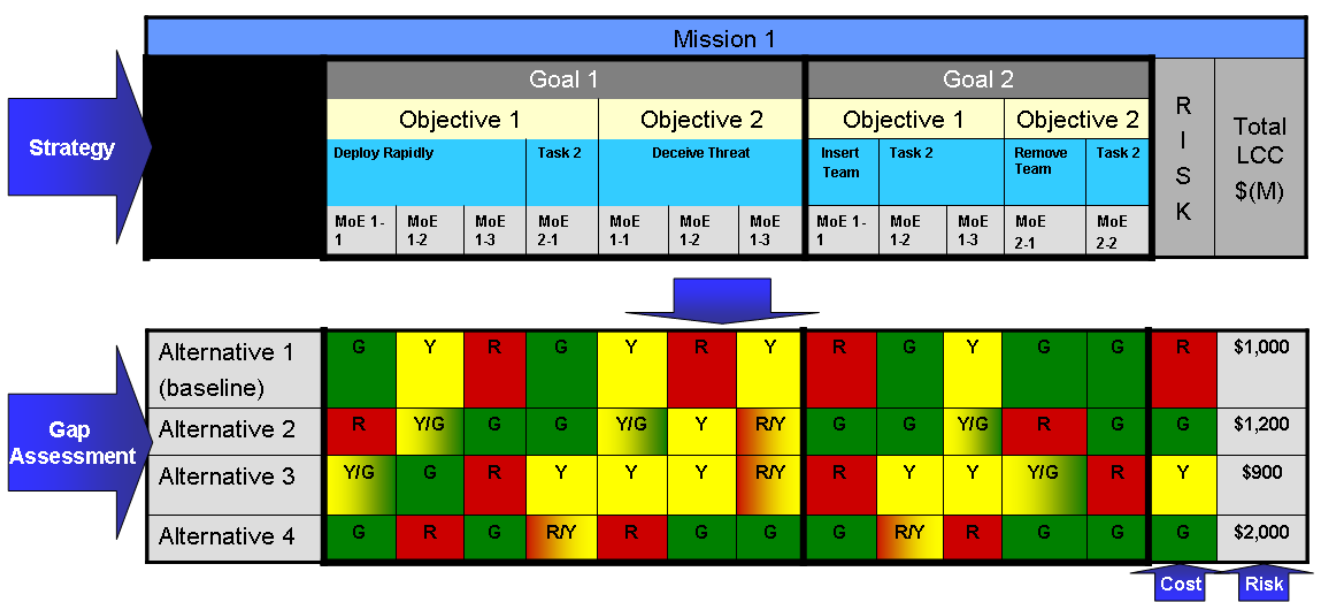

Figure 12: Force Matrix Model elements.

Since these tables can get large very fast, tools such as the Force Matrix Model ${ }^{\mathrm{TM}}$ can be used to assess these solutions. It is designed to allow the user to enter the matrix of data into an easy to understand hierarchical structure in order to evaluate solutions against a set of capabilities by combining effectiveness, cost, and risk. The result is an effective and fast approach to performing AoA. The methodology for determining a solution's value is discussed in more detail in the following section.

\section{Evaluating Solutions}

The effectiveness, cost, and risk of the identified solutions can be evaluated by using multi-attribute value theory (MAVT) which includes Analytical Hierarchy Process (AHP) and utility curves. There are several available open source material for AHP and MAVT methodology and should be referred to for details. These approaches are an alternative to expensive and time consuming modeling and simulation, which also integrate defense policy goals, force structure, and mission needs. MAVT uses

- Criteria or Measures of Performance (MOP) that are developed for each capability and then prioritized using the AHP process;

- An AHP process that uses a pair-wise comparison of capabilities and then ranks them using an arithmetic or geometric mean; for example, using geometric mean for prioritizing pair-wise comparisons calculated in the form $\mathrm{w}_{\mathrm{i}}=\left(\Pi \mathrm{a}_{\mathrm{i}, \mathrm{j}}\right)^{1 / \mathrm{n}}$;

- Utility curves use functions (s-curves) of the type

$$
\mathrm{y}=\mathrm{c}+(\mathrm{d}-\mathrm{c})\left[1-\mathrm{e}^{-\mathrm{A}(\mathrm{x}-\mathrm{a}) \mathrm{B}}\right], \mathrm{x} \geq \mathrm{a}
$$


(1) Develop Strategies
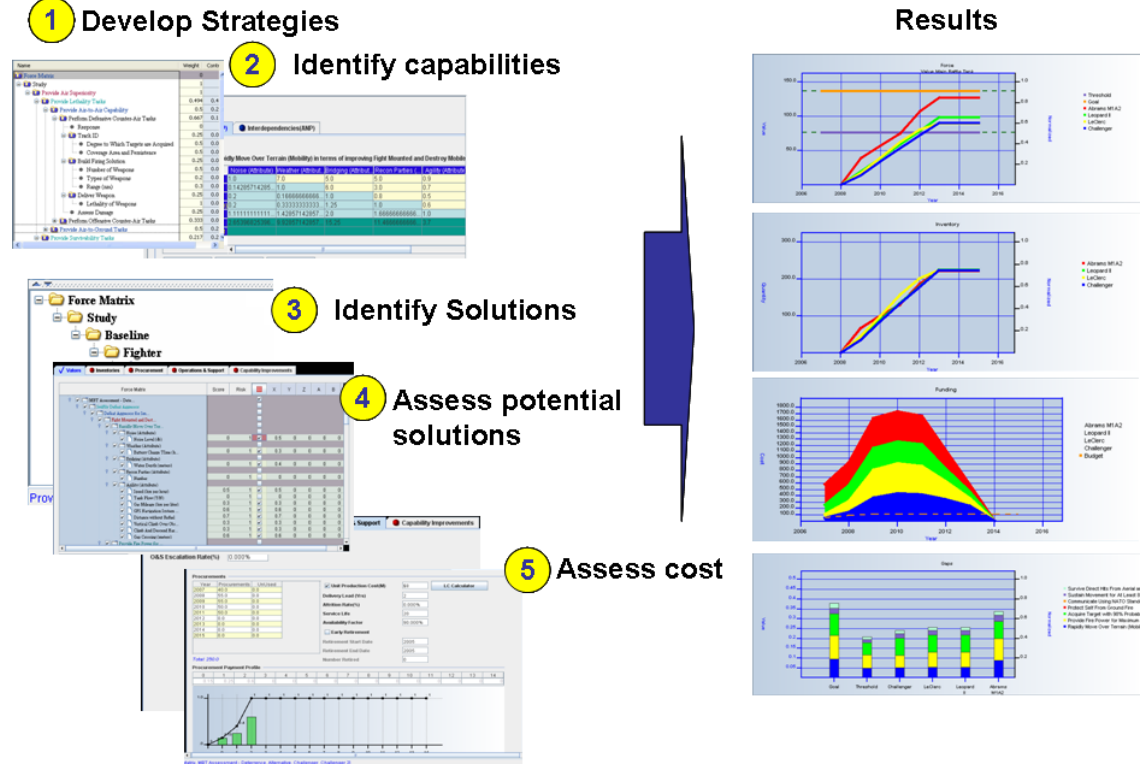

Figure 13: Force Matrix Model ${ }^{\mathrm{TM}}$.

for determining the value of a solution. S-curves use mathematics to mimic the way people make decisions and most often represent this decision thought process by allowing the decision maker to define the "preference" curve.

The goal of MAVT is to associate a value with each alternative in order to produce a ranking consistent with the utility of the capability. The Force Matrix Model ${ }^{\mathrm{TM}}$ uses AHP to prioritize the criteria (or capabilities) and utility curves to evaluate the solution and is described below.

The final result is a weighted average (or normalized ranking) of the capabilities and are rolled up into an overall value

Overall Value $=\Sigma \mathrm{w}_{\mathrm{i}} \mathrm{f}\left(\mathrm{MOP}_{\mathrm{i}}\right)$, where Score $=\mathrm{f}\left(\mathrm{MOP}_{\mathrm{i}}\right)$.

The function $\mathrm{f}\left(\mathrm{MOP}_{\mathrm{i}}\right)$ is an s-shaped utility curve and is determined using subject matter experts or through the use of more detailed simulation models. The function assumes that each capability is independent of each other. Force Matrix Model ${ }^{\mathrm{TM}}$ $\left(\mathrm{FMM}^{\mathrm{TM}}\right)$ uses a hybrid approach where it uses AHP for prioritizing missions, goals, objectives, and tasks and utility curves for scoring the solutions. This hybrid approach has its advantages in that large AHP tables can be avoided. And although util- 
ity curves can be difficult to produce, they do give a more realistic view of the capability by allowing the user to represent the curve in a non-linear fashion.

If some synergistic characteristics are present in the system, it may be possible to mathematically combine the values

$$
\begin{gathered}
\text { Overall Value }=\sum \mathrm{w}_{\mathrm{i}} \mathrm{f}\left(\mathrm{MOP}_{\mathrm{i}}\right)+\left[\mathrm{w}_{1} /\left(\mathrm{w}_{1}+\mathrm{w}_{2}+\ldots+\mathrm{w}_{\mathrm{r}}\right)\right] \mathrm{f}\left(\mathrm{MOP}_{1}\right) \mathrm{x} \\
{\left[\mathrm{w}_{2} /\left(\mathrm{w}_{1}+\mathrm{w}_{2}+\ldots+\mathrm{w}_{\mathrm{r}}\right)\right] \mathrm{f}\left(\mathrm{MOP}_{2}\right) \mathrm{x} \ldots}
\end{gathered}
$$

What we want, in effect, is to define synergy as an "added" value (for example, a fighter gets added value for being stealthy and possessing the ability to detect enemy targets). It also says that synergistic characteristics are dependent on each other and therefore result in some degradation when the capability values are multiplied by each other.

Although MAVT can be used to evaluate costs, some knowledge of the actual cost of a system is still needed. Evaluating costs for new systems can be a difficult and complex task and is generally done using other parametric models. However, for current systems, costs can be obtained from the original equipment manufacturer (OEM) or from open sources. It can then be used as part of the MAVT methodology to evaluate value or it can be applied directly to the solution to determine effectiveness over cost ratio.

There are two possible ways to evaluate risk. One is to define it as a measure of performance and calculate its value based on its priority and value

Overall Risk $=\mathrm{w}_{\text {perf }} \sum \mathrm{P}_{\mathrm{i}} \mathrm{C}_{\mathrm{i}}+\mathrm{w}_{\text {cost }} \sum \mathrm{P}_{\mathrm{i}} \mathrm{C}_{\mathrm{i}}+\mathrm{w}_{\text {schedule }} \sum \mathrm{P}_{\mathrm{i}} \mathrm{C}_{\mathrm{i}}$

where $\mathrm{P}$ is the probability of failure (or risk) and $\mathrm{C}$ is the consequence of failure (or impact).

The other way is to apply the risk to the capability and degrade it in the form

Degradation of capability from risk $=\mathrm{w}_{\mathrm{i}} \mathrm{f}\left(\mathrm{MOP}_{\mathrm{i}}\right) \times\left(1-\mathrm{P}_{\mathrm{i}} \mathrm{C}_{\mathrm{i}}\right)$.

Intended or unintended consequences must also be a factor in risk analysis. It is extremely important that these factors be thoroughly investigated and understood. Where a consequence is anticipated and is the possible outcome of an action (or risk), an unintended consequence is always unanticipated. For example, an aircraft under evaluation that uses a new communications technology will have an anticipated schedule risk. An unintended consequence to the new technology may be that it causes interference in other systems on the aircraft.

\section{Finding the Best Solution}

Although many non-viable alternatives were probably eliminated even before the assessment began, another screening process must be done on the remaining viable al- 
ternatives. Once all of the viable solutions are evaluated for value, cost, and risk, it is necessary to perform a subsequent analysis to eliminate the alternatives that do not meet specified requirements. Alternatives that appear to have high value may be eliminated because of excessively high cost. Likewise, an alternative may have a low cost, but does not have the capability to support the mission. Figure 14, taken from the Analysis of AoA Handbook, ${ }^{2}$ shows how a set of alternatives has been narrowed down based on cost, performance, schedule, and risk. It is up to management to make the ultimate decision. It may be necessary to refine and re-evaluate the solutions in order to find one solution. This means the solution will go through a series of refinements and further analysis to ensure that it is indeed a logical choice to support the strategy.

\section{Software Tools Used to Support Defense Acquisition Decisions}

Because of the complexity of capability-based assessments and acquisition planning, software tools are generally used to structure the problem and evaluate it. In order to determine the value of a capability, methods such as Analytical Hierarchy Process or Utility Theory can be used. Several commercial models exist such as Expert Choice or Decision Lens ${ }^{\circledR}$ which use AHP. Another tool called Force Matrix Model ${ }^{\mathrm{TM}}$ $\left(\mathrm{FMM}^{\mathrm{TM}}\right.$ ) developed by Lockheed Martin uses AHP and Utility Theory to determine value. All of these tools and methods ensure that transparency is incorporated, since neither method uses any factors or unknown calculations.

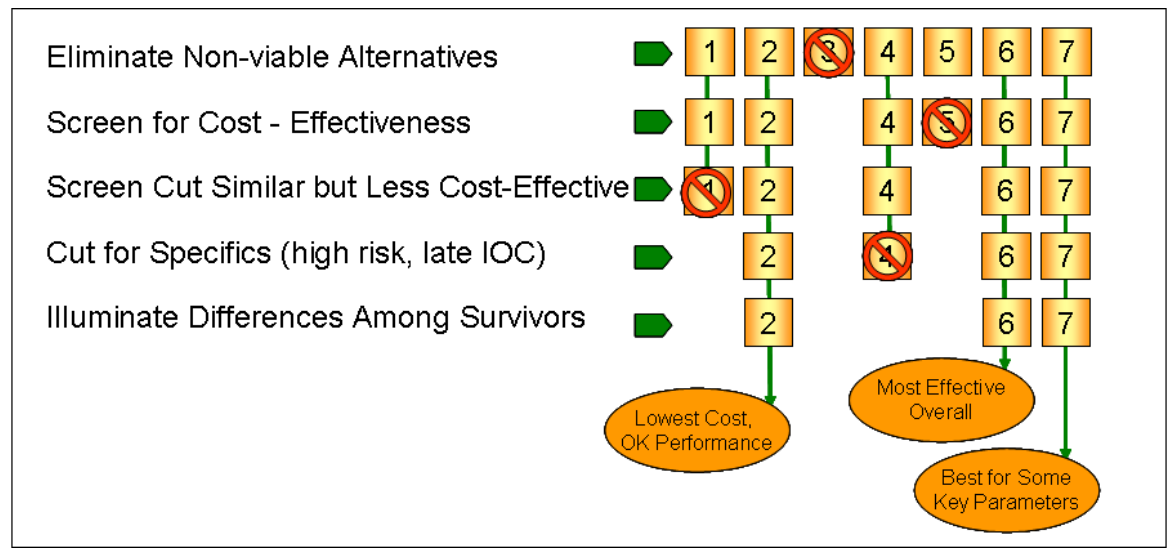

Figure 14: Elements of the Defense Resource Management Model. 


\section{Conclusion}

More national governments are requiring transparent force structure and analyticallybased acquisition decisions. However, determining the best solution to solve a country's gaps or issues in their defense posture can be frustrating, especially with a continuously changing global environment and unstable economies. The strategic planning process takes this variability into account, and to the maximum extent possible, focuses on the country's real needs and resources. If a fighter acquisition decision needs to be made, the five step strategic planning process will ensure the right requirements are identified and improve the likelihood of a successful decision. The strategy should account for environmental factors and be built upon realistic visions, missions and goals to ensure success. When objectives and measurable tasks are added, a solid strategy with the best possible set of requirements will be produced. Finally, an analysis of alternatives that includes gap (effectiveness), cost, and risk assessments, and evaluated with a tool like $\mathrm{FMM}^{\mathrm{TM}}$ will assist in finding the best possible solution.

As we have demonstrated throughout the paper, using the appropriate defense strategy process forces decision makers to identify the best solutions that will help meet the country's national security guidelines and its sovereignty. It is a collaborative and transparent process where all stakeholders have their concerns addressed, producing a solution that will be beneficial to all. Finally, this five step process is clear, easy to follow, analytically sound, and uses a team approach and produces best results.

\section{Bibliography:}

1. Director, Office of Force Transformation, Elements of Defense Transformation (Washington, D.C.: OSD Office of Force Transformation, October 2004), <http://handle.dtic.mil/100.2/ADA450716> (20 September 2010).

2. National Security Strategy (Washington, D.C.: The White House, May 2010), <www.whitehouse.gov/sites/default/files/rss_viewer/national_security_strategy.pdf> (20 September 2010).

3. Analysis of Alternatives (AoA) Handbook. A Practical Guide to Analyses of Alternatives (Kirtland AFB, NM: Office of Aerospace Studies, Air Force Materiel Command, July 2008).

4. Mats Lindgren and Hans Banhold, Scenario Planning: The Link between Future and Strategy (Palgrave MacMillan Press, 2003).

5. Department of Defense Directive 5000.2 (12 May 2003), Joint capabilities integration and development system, CJCS i3170.01e distribution: a, b, c, j, s, 11 May 2005.

6. Guide to Capability-Based Planning, TR-JSA-TP3-2-2004 (The Technical Cooperation Program, Joint Systems and Analysis Group, Technical Panel 3, MORS 
Workshop, October 2004), <www.mors.org/meetings/cbp/read/TP-3_CBP.pdf> (14 October 2010).

7. Alan G. Whittaker, Frederick C. Smith, and Elizabeth McKune, The National Security Policy Process: The National Security Council and Interagency System (Washington, D.C.: National Defense University, October 2010), <www.ndu.edu/ icaf/outreach/publications/nspp/docs/icaf-nsc-policy-process-report-10-2010.pdf> (26 October 2010).

8. Jeffrey D. Brake, Quadrennial Defense Review (QDR):Background, Process, and Issues, RS 20771 (Washington, D.C.: Congressional Research Service, June 2001).

9. Marjan van Herwijnen, Multi-attribute value theory (MAVT), Introduction, $<$ www.ivm.vu.nl> (12 October 2010).

10. Corey M. Collier, Jeffrey C. Kacala, A Cost-Effectiveness Analysis of Tactical Satellites, High-Altitude Long-Endurance Airships, and High and Medium Altitude Unmanned Aerial Systems for ISR and Communication Missions (Monterey, CA: Naval Postgraduate School, September 2008), <http://handle.dtic.mil/ 100.2/ADA488904> (11 October 2010).

\section{Notes:}

1 Analysis of Alternatives (AoA) Handbook. A Practical Guide to Analyses of Alternatives (Kirtland AFB, NM: Office of Aerospace Studies, Air Force Materiel Command, July 2008).

2 Analysis of Alternatives (AoA) Handbook.

ROBERT K. MURPHY is a senior manager for the Strategic Studies Group, Strategic Planning at Lockheed Martin Aeronautics Company. He has worked at Lockheed Martin Aeronautics Company for 22 years and is responsible for modeling and analysis in economics, force structures assessments, and capability based assessments. Prior experience includes three years at Honeywell working on life cycle cost modeling of naval torpedo programs. He holds a Bachelor of Mathematics degree from the University of Minnesota, Institute of Technology and a Bachelor of Arts in German from the University of Minnesota, College of Liberal Arts. He also holds a Masters of Science in Operations Research and a Masters of Engineering Management from Southern Methodist University.E-mail: bob.k.murphy@lmco.com.

SCOTT D. BEACH is a senior manager for the Strategic Studies Group, Strategic Planning at Lockheed Martin Aeronautics Company. He has worked at Lockheed Martin Aeronautics Company for three years and is responsible for international strategy assessments and development, supporting F-35, F-16, and C-130 market development worldwide. He also supports individual F-35 country strategy development and is the United States Navy (USN) subject matter expert. Prior to joining Lockheed Martin, he spent 26 years in the USN as a Naval Aviator where he held numerous command, operational, and planning assignments, which included several assignments with the international community. He holds a Bachelor of Science degree from the Texas A\&M University and a Masters in Public Administration from Auburn University.E-mail: scott.d.beach@Imco.com. 